\title{
Overexpression of thyroid hormone receptor $\beta 1$ is associated with thyrotropin receptor gene expression and proliferation in a human thyroid carcinoma cell line
}

\author{
S-T Chen ${ }^{1}$, H-Y Shieh ${ }^{2}$ J-D Lin ${ }^{3}$, K S S Chang ${ }^{1}$ and K-H Lin ${ }^{2}$ \\ ${ }^{1}$ Graduate Institute of Clinical Medicine, Chang-Gung University, Taoyuan, Taiwan, R.O.C. \\ ${ }^{2}$ Department of Biochemistry, Chang-Gung University, Taoyuan, Taiwan, R.O.C. \\ ${ }^{3}$ Division of Endocrinology and Metabolism, Chang Gung Memorial Hospital, Taoyuan, Taiwan, R.O.C. \\ (Requests for offprints should be addressed to K-H Lin, 259 Wen-hwa 1st Road, Department of Biochemistry, Chang-Gung University, Kwei-san, Taoyaun, \\ Taiwan, R.O.C.; Email: khlin@mail.cgu.edu.tw)
}

\begin{abstract}
To correlate the differentiation phenotype of two human thyroid cancer cell lines with their expression of various molecular markers, we analyzed the mRNA levels of four thyroid-specific genes, including thyrotropin receptor (TSHR), thyroglobulin (Tg), thyroid transcription factor-1 (TTF-1), and paired-box containing transcription factor-8 (PAX-8) genes. The results showed a differentiation-status-related pattern in which a welldifferentiated cell line (WRO) expressed all the four genes, in contrast to an anaplastic cell line (ARO) that expressed TTF-1 and reduced levels of TSHR, but no Tg or PAX-8 genes. Furthermore, to verify the finding of concomitant loss of $\beta$ subtype thyroid hormone receptor $(T R \beta)$ and TSHR gene expression in neoplastic thyroid tumors (Bronnegard et al. 1994), we examined the expres-
\end{abstract}

sion levels of TR $\beta 1$ gene in these cell lines. Whereas the WRO cells produced an abundant amount of TR $\beta 1$ protein detectable by immunoprecipitation, the ARO cells produced none. This new observation prompted us to investigate whether overexpression of TR $\beta 1$ protein in ARO cells might produce changes in the differentiation phenotypes. We found that the level of expression of the TSHR gene and the proliferative index of ARO cells were significantly upregulated in the cells stably transfected with wild-type TR $\beta 1$. These findings suggest that TR $\beta 1$ protein overexpression can affect the differentiation phenotypes and induce more efficient cell proliferation of the anaplastic ARO cells.

Journal of Endocrinology (2000) 165, 379-389

\section{Introduction}

Despite the fact that $\mathrm{L}-3,5,3^{\prime}$-tri-iodothyronine $\left(\mathrm{T}_{3}\right.$, the most active form of the thyroid hormones) regulates the differentiation and development of many organs through interaction with its receptors (Munoz \& Bernal 1997), it is believed that the growth and differentiation of thyroid cells are under the control of thyroid stimulating hormone (TSH) (Field 1991). However, the concept was challenged recently when loss of the $\alpha$ subtype thyroid hormone receptor $\left(\mathrm{TR} \alpha^{-/-}\right)$in knock-out mice was found to cause thyroid hypoplasia although the TSH concentration was not affected (Gauthier et al. 1999). There is evidence to indicate that $T_{3}$ modifies thyroid cell function and growth. For instance, $\mathrm{T}_{3}$ inhibits $\mathrm{TSH}$-induced iodine uptake, but promotes cell growth in a rat thyroid cell line, FRTL-5 (Akiguchi et al. 1992). Furthermore, $\mathrm{T}_{3}$ downregulates the TSH receptor (TSHR) promoter activity in CV-1 (monkey kidney cell line) cells overexpressing TRa1 (Saiardi et al. 1994). Clinically, Bronnegard et al.
(1994) found that the levels of expression of TR $\beta$ subtypes and TSHR genes were significantly lower in neoplastic than in normal thyroid tissues. Together, these findings suggest a role of TR as a nuclear receptor and transcription factor (Cheng 1995) that regulates thyroid-specific gene (such as TSHR) expression and cell growth.

Thyroid tumors that originate from follicular cells present a broad spectrum of clinical features, ranging from benign nodular hyperplasia and follicular adenoma to well (follicular) and poorly differentiated (anaplastic) malignant carcinoma. In addition to the clinical pleomorphic presentation, the life expectancy of patients also varies remarkably according to the histopathological types of the tumor. Thus efforts have been directed at early detection and treatment of malignant thyroid cancers. Even so, certain categories of thyroid neoplasms still carry a greater than expected fatality rate (Schneider 1991). To improve diagnostic sensitivity and specificity, molecular tumor markers that can help accurately predict the outcome of thyroid neoplasms are needed. TSHR, thyroglobulin (Tg), 
thyroperoxidase (TPO), thyroid transcription factor-1 (TTF-1) and paired-box containing transcription factor-8 (PAX-8) genes are good candidates as markers of the clinical behavior of tumors, because these genes are expressed exclusively in the thyroid and are strictly related to the developmental status (Zannini et al. 1992, Kimura 1997). Although a limited number of clinical studies produced discouraging results (Brabant et al. 1991, Ohta et al. 1991, Fabbro et al. 1994, Schuppert et al. 1996), the findings that oncogenic transformation of rat thyroid cell lines frequently leads to loss of TSHR (Berlingieri et al. 1990), TTF-1 (Francis-Lang et al. 1992b) and other thyroid differentiation markers suggest that these molecular markers may be useful for further characterization of degrees of malignancy in human thyroid cancers.

In the present study, we found that, whereas the well-differentiated WRO cell line exhibited relatively high TSHR mRNA and TR $\beta 1$ protein levels, the anaplastic ARO cell line showed an absence of TR $\beta 1$ protein and decreased TSHR mRNA levels. In ARO cells stably transfected with TR $\beta 1$ gene, the overexpression of TR $\beta 1$ protein was accompanied by increased amounts of TSHR protein and accelerated cell proliferation. The findings suggest an important role of TR $\beta 1$ in modulating differentiation and growth of this anaplastic thyroid cancer cell line.

\section{Materials and Methods}

\section{Cell lines and human tissues}

A well-differentiated (follicular) human thyroid cancer cell line (UCLA RO 82 W-1 (WRO); Estour et al. 1989) and an undifferentiated cell line (UCLA RO-81A-1 (ARO)) were kindly provided by Dr GJF Juillard (UCLA, Los Angeles, CA, USA). Both cell lines were cultured in RPMI 1640 medium supplemented with 10\% fetal calf serum (FCS), $2 \mathrm{mM}$ L-glutamine, $100 \mathrm{U} / \mathrm{ml}$ penicillin and $0.1 \mathrm{mg} / \mathrm{ml}$ streptomycin, at $37^{\circ} \mathrm{C}$ in a $\mathrm{CO}_{2}$ incubator. ARO cells overexpressing TR $\beta 1$ protein were created by stable transfection with a wild-type (wt) TR $\beta 1$ gene construct driven by human cytomegalovirus (CMV) promoter/enhancer in a neomycin-selectable expression vector, pcDNA3-51. Cells were transfected by means of cationic liposomes (Lipofectamine, Gibco-Brl, Gaithersburg, MD, USA) according to the manufacturer's instructions. Neomycin-resistant colonies were initially selected on plates containing $800 \mu \mathrm{g} / \mathrm{ml}$ geneticin (G418, Gibco-BRL), and maintained in culture medium containing $400 \mu \mathrm{g} / \mathrm{ml}$ geneticin. Colonies were individually examined by immunoprecipitation for the expression of TR $\beta 1$ protein. Two stable transfectant clones (ARO1 and ARO2) overexpressing TR $\beta 1$ protein, and one neomycin resistant clone (ARO-neo) without TR $\beta 1$ protein expression were selected for further analysis. As a control, normal tissue counterparts of thyroid tumors were excised and stored in a liquid nitrogen tank until required for use.

The Fischer rat thyroid cell line (FRTL-5) that preserves iodine-trapping and Tg synthesis was provided by Dr WJ DeVito (University of Massachusetts, Worcester, MA, USA). The FRTL-5 cells were cultured in Coon's Modified Ham's F12 medium supplemented with 5\% calf serum, $100 \mathrm{U} / \mathrm{ml}$ penicillin, $0 \cdot 1 \mathrm{mg} / \mathrm{ml}$ streptomycin, and 6-hormone preparation $(6 \mathrm{H}: 1 \mathrm{mU} / \mathrm{ml}$ bovine $\mathrm{TSH}$, $10 \mu \mathrm{g} / \mathrm{ml}$ bovine insulin, $5 \mu \mathrm{g} / \mathrm{ml}$ human transferrin, $2 \mathrm{ng} / \mathrm{ml}$ gylcyl-L-histidyl-L-lysine, $10 \mathrm{ng} / \mathrm{ml}$ somatostain and $0.36 \mathrm{ng} / \mathrm{ml}$ hydrocortisone; Sigma, St Louis, MO, USA). Before the assay of TSH function, cells were preincubated with culture medium devoid of TSH $(5 \mathrm{H})$ for 7 days. On the day of experiment, the medium was replaced with hormone-free, 5\% calf-serumsupplemented F12 medium.

\section{Plasmids}

Thyroid responsive element (TRE)-containing reporter genes (pal-luciferase driven by thymidine kinase promoter) and the wtTR $\beta 1$ expression vector peA101 were gifts from Dr SY Cheng (NIH, Bethesda, MD, USA). TR $\beta 1$ cDNAs were reverse-transcribed from ARO and WRO cells, and cloned into the pGEM-T vector (Promega, Madison, WI, USA) as described previously (Lin et al. 1997). The wtTR $\beta 1$-containing expression vector pcDNA3-51 was constructed by inserting wtTR $\beta 1$ cDNA isolated from pCLC-51 (Lin et al. 1991) into the EcoRV/NotI site of a mammalian expression vector, pcDNA3 (Invitrogene, Carlsbad, CA, USA).

\section{In vitro trancription/translation of TR $\beta 1$ protein}

To test the structural and functional integrity of TR $\beta 1$ proteins, peA101 and pGEM-T vectors containing TR $\beta 1$ cDNAs cloned from both thyroid cancer cell lines were translated in vitro with the TNT (In vitro transcription/ translation kit) rabbit reticulocyte lysate kit (Promega), according to the manufacturer's instructions. Proteins were analyzed by sodium dodecyl sulfate-polyacrylamide gel electrophoresis (SDS-PAGE) and confirmed by immunoprecipitation.

\section{$R N A$ preparation and reverse transcription-polymerase chain reaction ( $R T-P C R)$}

Total RNA was extracted with Trizol reagent (Gibco$\mathrm{BRL}$ ). In brief, cells or minced tissues were lysed in an adequate volume of Trizol reagent according to the manufacturer's instructions. After chloroform extraction and high-speed centrifugation $(12000 \mathbf{g}, 15 \mathrm{~min})$, total RNA was purified and stored at $-70{ }^{\circ} \mathrm{C}$ until required for use.

The expression of TR transcripts was detected by subtype-specific $5^{\prime}$ - and $3^{\prime}$-primers corresponding to the 
full-length coding regions of TR $\alpha 1, \alpha 2$, and $\beta 1$, as previously described (Lin et al. 1996). Transcripts of TSHR, Tg, TPO, TTF-1, and PAX-8 genes were analyzed by primers amplifying regions of specific sizes as follows: TSHR (1478-2275): 5'-GCCTCTGTAGACC TCTACACTCAC-3' (sense), 5'-GTTTTCAATCAGT TCATAGACATC-3' (anti-sense); Tg (2143-2749): 5'CAGAGTGCTACTGTGTTGATGC-3' (sense), 5'-TC ATCCACACACCAGCAGTTCC-3' (anti-sense); TPO (365-782): 5'-ACTCAACAATCACAGCAT CC-3' (sense), 5'-TGCTCTGTGGTGTGAACG-3' (anti-sense); TTF1 (241-780): 5'-CTACAAGAAAGTGGGCATGG-3' (sense), 5-GTGGGCGTCAGGTGGATCAT-3' (antisense); PAX-8 (203-657): 5'-GCGGAATTCGGCG AT-3' (sense), 5'-CGCAAGCTTCAACTA-3' (antisense). The PCR reactions were carried out in $10 \mathrm{mM}$ Tris- $\mathrm{HCl} / \mathrm{pH} 8 \cdot 3,50 \mathrm{mM} \mathrm{KCl}, 1 \cdot 5 \mathrm{mM} \mathrm{MgCl} 2,0 \cdot 1 \mathrm{mM}$ dNTP with specific primers, and $0 \cdot 125 \mathrm{U} / \mu \mathrm{l}$ Taq DNA polymerase (Promega) under the following cycling conditions: 30 cycles at $94{ }^{\circ} \mathrm{C}$ for $1 \mathrm{~min}, 54{ }^{\circ} \mathrm{C}$ for $2 \min , 72{ }^{\circ} \mathrm{C}$ for $2 \mathrm{~min}$, followed by extension of $1 \mathrm{~min}$ at each $72^{\circ} \mathrm{C}$ cycle for five additional cycles. To compare the levels of expression of the TSHR gene in ARO cells with or without TR $\beta 1$ overexpression, cDNAs reversetranscribed from the parental and stably transfected ARO cell lines were semi-quantitatively amplified with the coexistence of TSHR and $\beta$-actin primers at a fixed molar ratio $(1: 1)$. After fractional gel electrophoresis and ethedium bromide staining, the densities of bands specific for TSHR and $\beta$-actin fragments were measured with a densitometer (Personal Densitometer SI, Molecular Dynamics Inc., Sunnyvale, CA, USA). For comparison of the relative levels of TSHR gene expression in indicated cells, the $\beta$-actin gene served as an internal control to normalize the coamplified TSHR gene.

\section{Immunoprecipitation and Western blotting}

The levels of expression of TR and TSHR proteins were determined by immunoprecipitation (Lin et al. 1995) and Western blot (Lin et al. 1997) as described previously. Monoclonal antibodies (mAbs) specific for TSHR (MA3$217,1: 500 \times$ dilution), TR $\alpha 1$ (C4, $1 \mu \mathrm{g} /$ reaction), and TR $\beta 1$ (J52, $1 \mu \mathrm{g} /$ reaction) were purchased from Affinity BioReagents, Golden, CO, USA or Santa Crutz Biotechnology, Santa Crutz, CA, USA. After visualization with autoradiography at $-70{ }^{\circ} \mathrm{C}$ or enhanced chemiluminescence detection (ECL chemiluminescence kit; Amersham Pharmacia Biotech, Piscata-Way, NJ, USA), the densities of the 47, 55, and $\sim 80 \mathrm{kDa}$ bands specific for TR $\alpha 1$, TR $\beta 1$ and TSHR proteins, respectively, were measured by densitometry. To assure equivalent loading in the immunoprecipitation assay, aliquots of cell lysates precipitated with 12\% trichloroacetic acid (Sigma) were adjusted and standardized with a $\beta$-counter (Packard, Meriden, CT, USA) before assays. Equivalent loading in Western blots was ascertained by re-probing with $\beta$-actin (1: $1000 \times$ dilution, Boehringer Mannheim, Mannheim, Germany).

\section{$T_{3}$ transactivation activities}

ARO, ARO1, ARO2, and ARO-neo cells were tested for their $\mathrm{T}_{3}$ transactivation activities as described previously (Lin et al. 1997). In brief, cells were transfected with $1 \mu \mathrm{g}$ TRE-containing reporter gene that had been pre-incubated with $5 \times$ Lipofectamine $(\mathrm{v} / \mathrm{v})$; after $5 \mathrm{~h}$ of incubation with serum free Dulbecco's Modified Eagle Medium (Gibco Brl), the reaction was stopped by the addition of $10 \% \mathrm{~T}_{3}$-depleted FCS. After overnight culture, the transfected cells were shifted to culture medium containing the indicated $\mathrm{T}_{3}$ concentrations $(0,1,10$ or $50 \mathrm{nM}$ ) for an additional $48 \mathrm{~h}$, at which point luciferase activities were assayed with a luminator (AutoLumat LB953, EG \& G Berthod, Wildbad, Germany). The transfection efficiency was normalized to the protein concentration of the lysates.

\section{Assays for intracellular cyclic AMP and calcium concentrations}

The generation of intracellular cAMP was measured by the $\left[{ }^{3} \mathrm{H}\right]$ cAMP assay system (Amersham Pharmacia, Amersham Place, Bucks, UK). Briefly, cells were submerged in $1.5 \mathrm{ml} 200 \mu \mathrm{M} / \mathrm{ml}$ isobutyl methyl xanthine (Sigma) containing Krebs-Ringer-Hepes buffer $(130 \mathrm{mM}$ $\mathrm{NaCl}, 5 \mathrm{mM} \mathrm{KCl}, 1.2 \mathrm{mM} \mathrm{MgSO}$, $1.2 \mathrm{mM} \mathrm{CaCl}$, $20 \mathrm{mM}$ Hepes, $1.2 \mathrm{mM} \mathrm{Na}_{2} \mathrm{HPO}_{4}$ and $10 \mathrm{mM}$ glucose) before $20 \mu \mathrm{M}$ forskolin (Sigma), or $200 \mu \mathrm{IU} / \mathrm{ml} \mathrm{TSH}$ (Sigma) was added. After $30 \mathrm{~min}$ of incubation at $37^{\circ} \mathrm{C}$, cells were fixed and harvested by scraping. Cell lysates were centrifuged and the supernatants dried in a speed vacuum and re-dissolved in $50 \mu \mathrm{l}$ Tris-EDTA. With the generation of cellular cAMP, the $\left[{ }^{3} \mathrm{H}\right]$ cAMP competed for cAMP-binding protein binding. Thus the amount of the endogenous cAMP was determined by the measurement of the free $\left[{ }^{3} \mathrm{H}\right] \mathrm{cAMP}$, using a $\beta$-counter.

To determine the intracellular calcium concentration, we followed the method described by Metcalfe et al. (1998), with minor modifications. Briefly, after reaching $80 \%$ confluence on collagen-coated $22 \times 9 \mathrm{~mm}$ coverslips, cells were shifted to serum free medium for overnight culture before the assay. After a 45-min incubation with $5 \mu \mathrm{M}$ fura-2 AM (Molecular Probes, Eugene, OR, USA), cells were washed and incubated with $1.8 \mathrm{mM} \mathrm{CaCl}{ }_{2}$ containing phocal solution $(10 \mathrm{mM}$ Hepes, $125 \mathrm{mM}$ $\mathrm{NaCl}, 5 \mathrm{mM} \mathrm{KCl}, 10 \mathrm{mM}$ glucose, $2 \mathrm{mM} \mathrm{MgCl}_{2}$, $0.5 \mathrm{mM} \mathrm{NaH} \mathrm{PO}_{4}, 5 \mathrm{mM} \mathrm{NaHCO}$ ). After the procedure, the coverslips were placed diagonally in a cuvette for measurement. A bolus each of $200 \mu \mathrm{IU} / \mathrm{ml} \mathrm{TSH}$, $10 \mathrm{mM}$ calcium ionophore (ionomycin, Sigma), and $500 \mathrm{mM}$ calcium chelating agent (EGTA, Sigma) was injected at 50, 150 and $300 \mathrm{~s}$ respectively. With fixed 
(a)

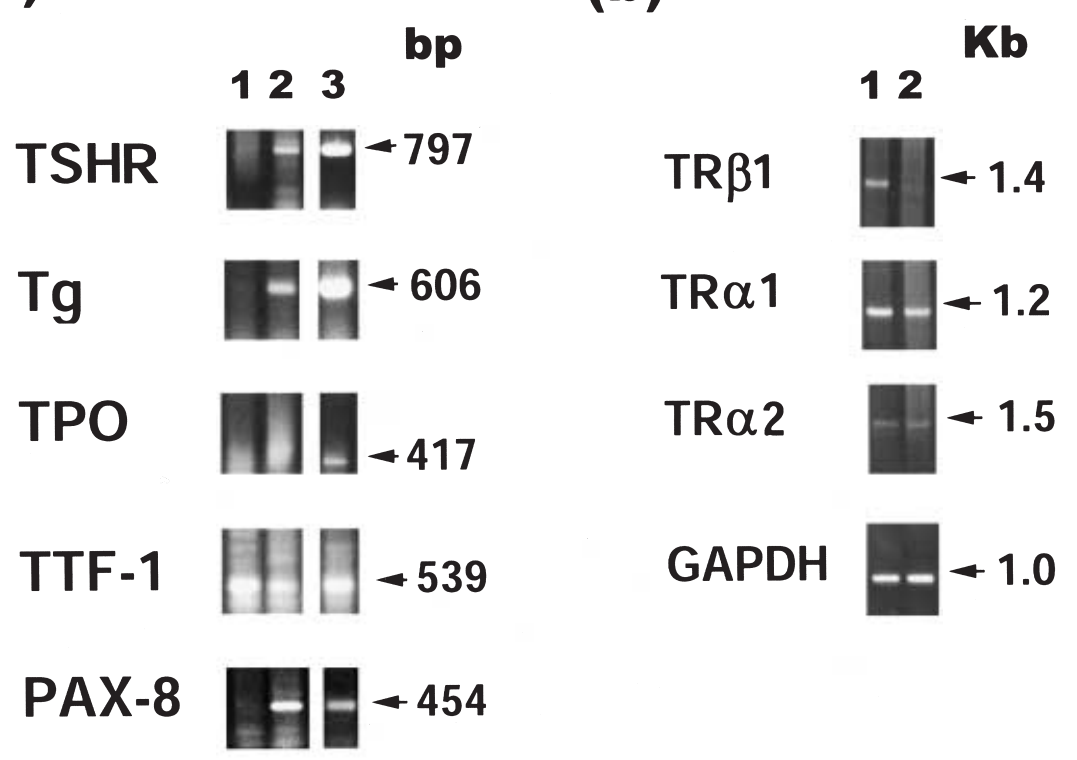

Figure 1 PCR amplification of transcripts for (a) TSHR, Tg, TPO, TTF-1 and PAX-8 and (b) TR subtypes $\alpha 1, \alpha 2$ and $\beta 1$ by RT-PCR. Total RNA extracted from the human thyroid cancer cell lines ARO and WRO (lanes 1 and 2 respectively) and normal thyroid tissue (lane 3) was reverse transcribed and amplified with specific primers, as described in Materials and Methods. The size of each amplified CDNA is indicated. The glyceraldehyde phosphate dehydrogenase $(\mathrm{GAPDH})$ gene served as the internal control.

excitation wavelengths of 340 and $380 \mathrm{~nm}$ and an emission wavelength of $510 \mathrm{~nm}$, the change in intracellular calcium content was recorded every $0 \cdot 2 \mathrm{~s}$ using a fluorescence spectrophotometer (Hitachi, Tokyo, Japan). Raw data were analyzed by the F-4500 intracellular calcium measurement system (Hitachi).

\section{Cell cycle analysis and cell proliferation}

The effect of TR $\beta 1$ overexpression on cell growth was determined by DNA flow cytometry and a Coulter counter. Cells were harvested at $90 \%$ confluence, washed, and resuspended in $1 \times$ phosphate buffered saline $(\mathrm{PBS})$ to a concentration of $1 \times 10^{6}$ cells $/ \mathrm{ml}$. After fixation in $80 \%$ alcohol, cells were incubated with $0.05 \%$ RNase and $0.5 \%$ Triton $\mathrm{X}$ at $37^{\circ} \mathrm{C}$ for $1 \mathrm{~h}$. DNA content was measured by a Becton Dickinson FACScan flow cytometer (Becton Dickinson, Mountain View, CA, USA) after staining with $50 \mu \mathrm{g}$ propidium iodine (PI, Sigma). Red fluorescence (PI) was collected through a $585 \mathrm{~nm}$ filter. Data were analyzed with the CellQuest and ModFit $2 \bullet 0$ softwares. The proliferative index was the ratio derived from dividing the percentage of cells in synthetic (S) and gap/mitosis $(\mathrm{G} 2 / \mathrm{M})$ phases by the percentage of cells in gap (G1/G0) phases.

After seeding of $2 \times 10^{5}$ cells $/ 60 \mathrm{~mm}$ dish, the cell number was determined for five subsequent days, from the day after seeding (day 0 ) to day 4 , using a cell counter (Coulter's Electronics, Luton, Beds, England) according to the manufacturer's instructions. The result was averaged from at least three independent experiments, each in duplicate. The cell number obtained from the Coulter counter was corrected by a hemocytometer at regular intervals.

\section{Results}

Levels of expression of thyroid-specific genes and TR subtypes are related to differentiation status in HTC cell lines

We characterized the phenotypic expression of thyroidspecific genes (TSHR, Tg, TPO, TTF-1 and PAX-8) in two human thyroid carcinoma (HTC) cell lines by means of RT-PCR (Fig. 1a). The expression of the TTF-1 gene in all cell lines was consistent with its thyroid epithelial origin, but the other thyroid-specific genes were heterogeneously expressed in the two HTC cell lines. As demonstrated by PCR-amplification, WRO cells preserved the character of a well-differentiated phenotype by showing the expression of TSHR, Tg, and PAX-8, but not TPO genes $\left(\mathrm{TSHR}^{+} \mathrm{Tg}^{+} \mathrm{PAX}-8^{+} \mathrm{TPO}^{-}\right.$); however, the levels of expression of these genes were remarkably reduced in the anaplastic ARO cells $\left(\mathrm{TSHR}^{ \pm} \mathrm{Tg}^{-} \mathrm{PAX}-\right.$ $\left.8^{-} \mathrm{TPO}^{-}\right)$. This finding suggests that the expression of 
(a)

\section{ARO WRO}

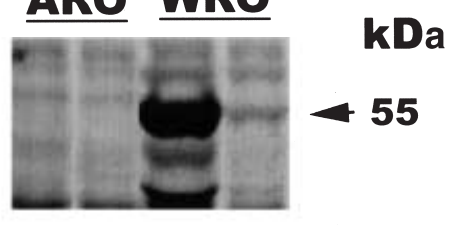

(b)

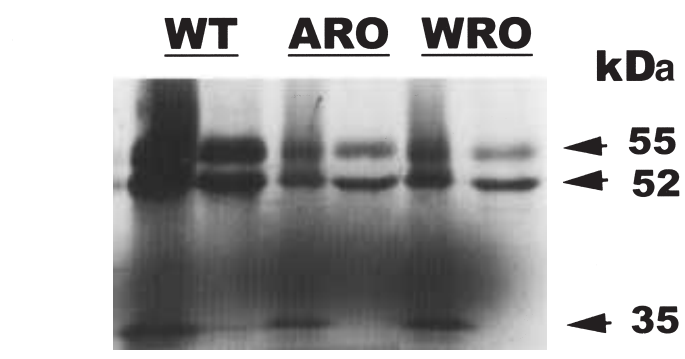

Figure 2 Expression of TR $\beta 1$ protein in two human thyroid cancer cell lines. Immunoprecipitation was performed as described in Materials and Methods. (a) The mAb 552 specifically precipitated the endogenous $55 \mathrm{kDa}$ TR $\beta 1$ protein in WRO cells but not in ARO cells. The non-specific MOPC21 antibody was applied as a negative control. (b) In vitro translated TR $\beta 1$ proteins obtained from cDNAs representing the wild type (WT) or that cloned from ARO and WRO cell lines were analyzed. Transcripts that arose from different internal ATG sites of the TR $\beta 1$ gene were in vitro translated and revealed as three bands $(55,52$ and $35 \mathrm{kDa})$ on SDS-PAGE analysis. After incubation with the mAb J52, only the 55 and $52 \mathrm{kDa}$ TR $\beta 1$ proteins were immunoprecipitated.

TSHR, Tg, and PAX-8 genes in the two HTC cell lines is related to differentiation status. The absence of TPO gene expression in both the well-differentiated and the anaplastic cell lines implies that TPO gene expression is exceptionally sensitive to neoplastic transformation.

The expression of TR subtypes was analyzed at the RNA and protein levels. Although the signals for transcripts of TR subtypes were not detectable by Northern blot (data not shown), RT-PCR effectively amplified the full-length transcripts of TR $\alpha 1, \alpha 2$ and $\beta 1$ from both HTC cell lines (Fig. 1b). High stringent hybridization to the probes derived from wtTR subtype plasmids confirmed the nature of these PCR products (data not shown). Notably, when the TR proteins were analyzed by immunoprecipitation, they showed distinctive patterns of expression (Fig. 2a). Although TR $\alpha 1$ protein was undetectable in both cell lines (data not shown), TR $\beta 1$ protein was abundantly expressed in WRO, but was absent from the ARO cell line.
The TR $\beta 1$ gene was not rearranged or deleted in the ARO cell line

To exclude the possibility that the endogenous TR $\beta 1$ gene was mutated in ARO cells, high molecular weight DNA and full-length TR $\beta 1$ cDNA cloned from ARO cells were analyzed by Southern blot analysis (data not shown). Furthermore, products of the in vitro translated TR $\beta 1$ cDNA were studied by SDS-PAGE analysis (Fig. $2 \mathrm{~b})$. No evidence suggesting rearrangement or deletion of the endogenous TR $\beta 1$ gene was found. In addition, immunoprecipitation by the $\mathrm{mAb} J 52$ suggested that proteins in vitro translated from either the wtTR $\beta 1 \mathrm{cDNA}$ or the ARO-cell-derived TR $\beta 1$ cDNA share the common epitope (Fig. 2b). Nevertheless, the fact that the exogenously introduced wtTR $\beta 1$ gene but not the endogenous gene transcripts were effectively processed intracellularly to yield TR $\beta 1$ proteins indicates that, if the instability of the transcript or its posttranslational degradation was responsible for the lack of the latter protein, then these defects did not exist for the former. Whether there was a complementation between the defective gene of the former and the non-defective, wt genes of the latter remains to be elucidated.

\section{Overexpression of wtTR $\beta 1$ protein enhances $T_{3}$} transactivating activities in ARO cells

ARO cells that transfected with wtTR $\beta 1$-expressing vector were screened for TR $\beta 1$ overexpression by immunoprecipitation. Two transfectants with TR $\beta 1$ protein overexpression were selected (ARO1 and ARO2 in Fig. $3 \mathrm{a})$. To test the functional integrity of the overexpressed TR $\beta 1$ protein, $T_{3}$ transactivation activities were assayed in the parental and TR $\beta 1$ stably transfected ARO cells. After transient transfection with a TRE-containing reporter gene (pal), the reporter activity showed a greater $T_{3}$ response, in a concentration-dependent manner, in both ARO1 and ARO2 than it did in ARO and ARO-neo cells (Fig. 3b). However, under $\mathrm{T}_{3}$ depletion the transactivating activities of ARO1 and ARO2 were similar to that of the parental ARO cells. This result shows that the overexpressed wtTR $\beta 1$ proteins were functionally active to transactivate downstream genes in response to $T_{3}$ in both ARO transfectants.

TR $\beta 1$ protein overexpression activates TSHR gene expression in ARO cells

The simultaneous absence of the TR $\beta 1$ protein and thyroid differentiation markers in ARO cells gave us the opportunity to study the regulatory effect of TR $\beta 1$ on the expression of differentiation-dependent genes. We found that the level of expression of TSHR, but not those of the other differentiation markers, was changed in ARO cells overexpressing TR $\beta 1$ (data not shown). To determine to 
(a)

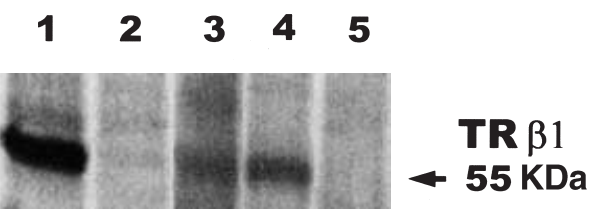

(b)

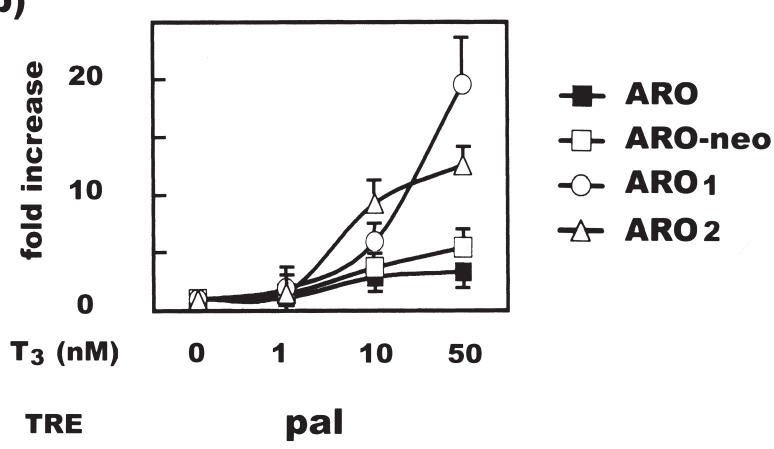

Figure 3 Characterization of stable ARO transfectants overexpressing TR $\beta 1$. (a) TR $\beta 1$ proteins were immunoprecipitated in WRO (lane 1) and two stable ARO transfectants (ARO1 and ARO2 in lanes 3 and 4), but not in ARO (lane 2) and the control neomycin-resistant ARO transfectant (ARO-neo, lane 5). (b) A TRE-containing reporter gene (pal) was transiently transfected to $\mathrm{ARO}$ and the two TR $\beta 1$-overexpressing transfectants (ARO1 and ARO2) to test the transactivating activity of $T_{3}$ at the concentrations indicated. The relative fold increase induced by $T_{3}$ compared with the basal transactivating activity of cells cultured in $\mathrm{T}_{3}$-depleted medium is shown. $\mathrm{T}_{3}(10$ and $50 \mathrm{nM})$ induced significantly greater transactivating activities in both ARO1 and ARO2 cells than in the parental ARO cells and the control ARO-neo cells. Values are means \pm S.E.M. of three independent experiments, each performed in duplicate.

what extent the TSHR gene was regulated by TR $\beta 1$, we performed semi-quantitative RT-PCR and Western blot analyses. The TSHR transcript levels were increased by approximately threefold after standardization against the internal control (RT-PCR, Fig. 4a). To a similar extent, the level of expression of TSHR protein was increased 2.6- and 6.7-fold in ARO1 and ARO2 cells respectively (Fig. 4b). These findings indicate that the exogenously introduced TR $\beta 1$ gene induced de novo production of TR $\beta 1$ protein and a greater concentration of TSHR protein in the anaplastic ARO cell line.

Stable ARO transfectants that overexpress TR $\beta 1$ and TSHR proteins show accelerated cell proliferation and DNA synthesis

The cell number and proliferative index were analyzed in the parental and TR $\beta 1$-overexpressing ARO cells. Cell proliferation (Fig. 5a) and DNA contents (Fig. 5b) were significantly increased in the TR $\beta 1$-overexpressing transfectants (ARO1 and ARO2 cells), but not in the parental (a)

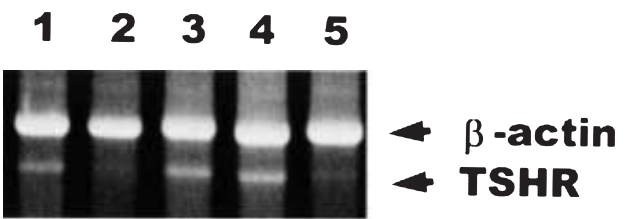

(b)
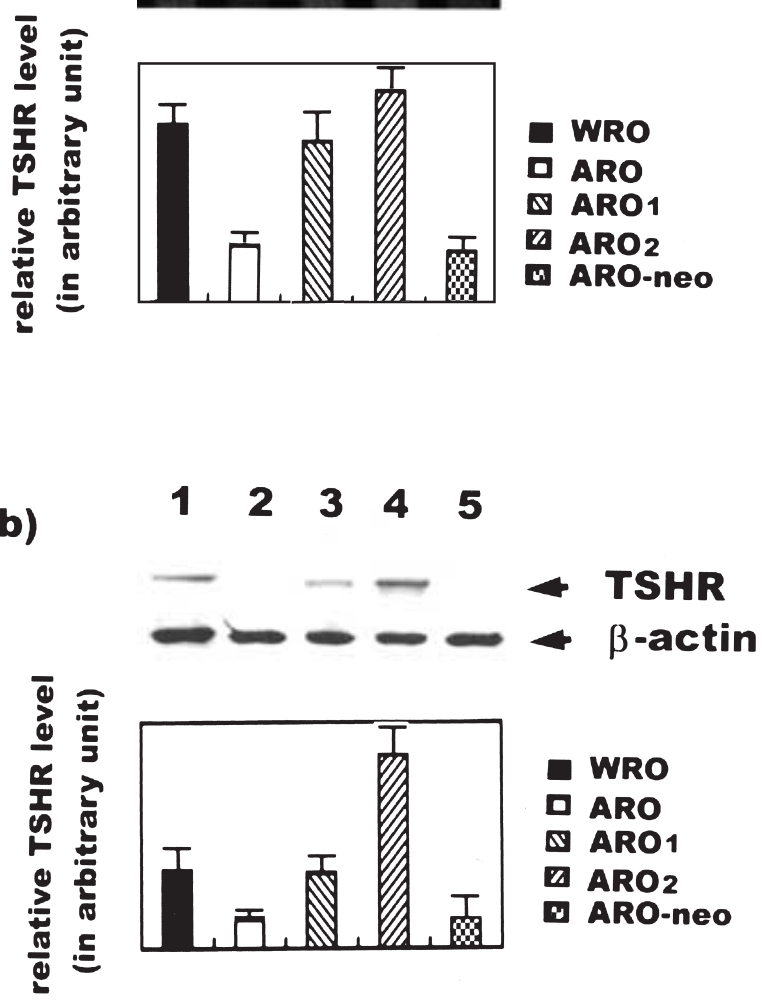

Figure 4 Expression of the TSHR gene in parental ARO and two TR 31 -overexpressing ARO cell lines (ARO1 and ARO2) was detected by (a) semiquantitative RT-PCR and (b) Western blot analysis as described in Materials and Methods. Upper panels show the levels of expression of the TSHR gene in WRO (lane 1), ARO, ARO1, ARO2 (lanes 2-4) and ARO-neo (lane 5) cell lines respectively. Lower panels show the relative density representing the level of expression of the TSHR gene for each cell line indicated. (a) After standardization against $\beta$-actin, the levels of TSHR gene expression in ARO1 and ARO2 cells were significantly greater than those in the ARO and ARO-neo cells. (b) Western blot analysis showed a marked increase in TSHR protein concentrations in ARO1 and ARO2 cells compared with the parental ARO cells. Values are means \pm S.E.M. of three independent experiments.

cells or in the TR $\beta 1$-protein-negative transfectant (AROneo). As measured by a Coulter counter, the cell number was significantly increased in the TR $\beta 1$-overexpressing transfectants (1.79- and 1.83-fold increases in ARO1, and 1.36- and 1.6-fold increases in ARO2 cells compared with ARO and ARO-neo cells on the 3rd and 4th days respectively; Fig. 5a). Furthermore, depletion or resupplementation of $\mathrm{T}_{3}$ did not change the growth velocity of any cell line (data not shown). Similarly, when the growth rate 
(a)

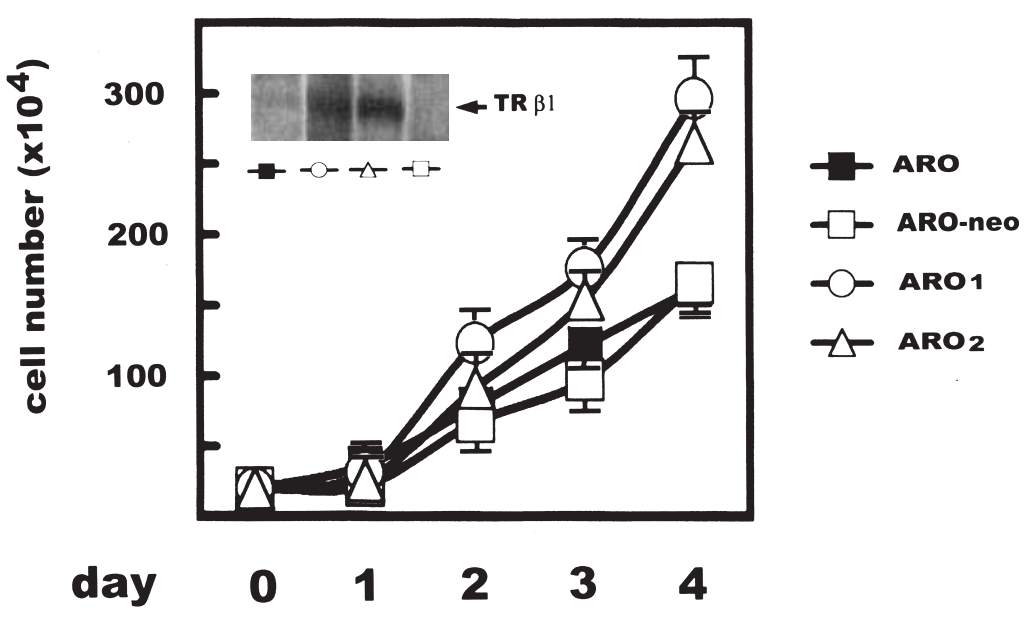

(b)
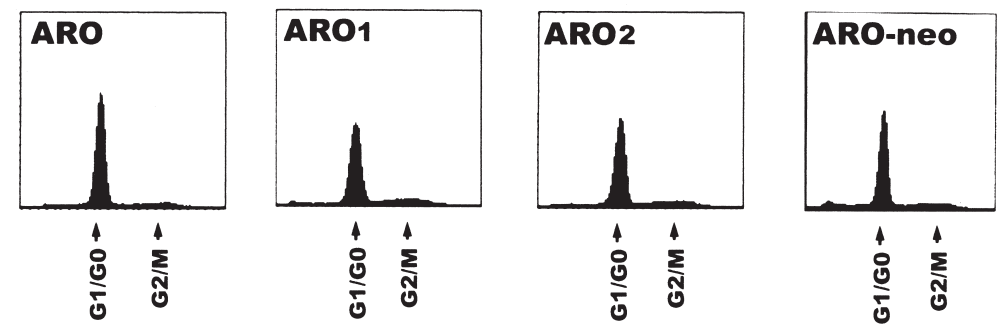

\begin{tabular}{ccccc} 
cells & ARO & \multicolumn{1}{c}{ ARO1 } & \multicolumn{1}{c}{ ARO 2} & \multicolumn{1}{c}{ ARO-neo } \\
\hline G1/GO & $90.3 \pm 0.2$ & $76.3 \pm 3.4$ & $80.3 \pm 1.9$ & $86.0 \pm 2.5$ \\
S & $5.7 \pm 0.1$ & $15.8 \pm 3.5$ & $12.2 \pm 0.9$ & $9.0 \pm 2.2$ \\
G2/M & $4.1 \pm 0.2$ & $8.0 \pm 0.3$ & $7.5 \pm 1.0$ & $5.0 \pm 0.2$ \\
\hline $\begin{array}{c}\text { proliferative } \\
\text { index }\end{array}$ & 0.11 & 0.31 & 0.25 & 0.16
\end{tabular}

Figure 5 Proliferative rates of ARO cells and their stable transfectants with or without TR $\beta 1$-overexpression are illustrated by (a) cell number and (b) DNA content. (a) Proliferative rates of ARO1 and ARO2 cells overexpressing TR $\beta 1$ protein were significantly greater than those of the ARO and ARO-neo cells without TR $\beta 1$ overexpression. (b) DNA flow cytometry showed significantly greater proliferative indices (summation of percentages of cells in $\mathrm{S}$ and G2/M phases, divided by percentage of cells in G0/G1 phases) in the two TR $\beta 1$-overexpressing ARO transfectants (ARO1, and ARO2) compared with the parental ARO cells. Values are means \pm S.E.M. of three independent experiments, each performed in duplicate.

was determined as the proliferative index, a remarkable population shift from the $\mathrm{G} 1 / \mathrm{G} 0$ phases to the $\mathrm{S}$ phase was observed in both ARO1 and ARO2 cells compared with both the parental ARO and ARO-neo cells (Fig. 5b).

TSHR overexpression did not improve the TSH response in the TR $\beta 1$-overexpressing ARO transfectants

To see whether the enhanced cell proliferation was related to the overexpression of TSHR in ARO1 and ARO2 cells, the TSH response in terms of intracellular cAMP and calcium influx was determined, and the results compared with those in WRO and ARO cells. As a positive internal control, these cells were tested with forskolin and ionomycin. Despite the fact that all the tested cells responded to forskolin and ionomycin, a TSH bolus $(200 \mu \mathrm{IU} / \mathrm{ml}) \mathrm{did}$ not improve either the intracellular cAMP $(15 \%$ and $11 \%$ in ARO1 and ARO2 cells, in contrast to $3 \cdot 4 \%$ in ARO and $13.3 \%$ in WRO cells), or the calcium influx of both TR $\beta 1$ and TSHR-overexpressing ARO transfectants (Fig. 6). 
(a)

$$
\begin{aligned}
& \text { Forskolin } 20 \mu \mathrm{M} \\
& \square \text { TSH } 200 \mu \mathrm{IU} / \mathrm{mI}
\end{aligned}
$$

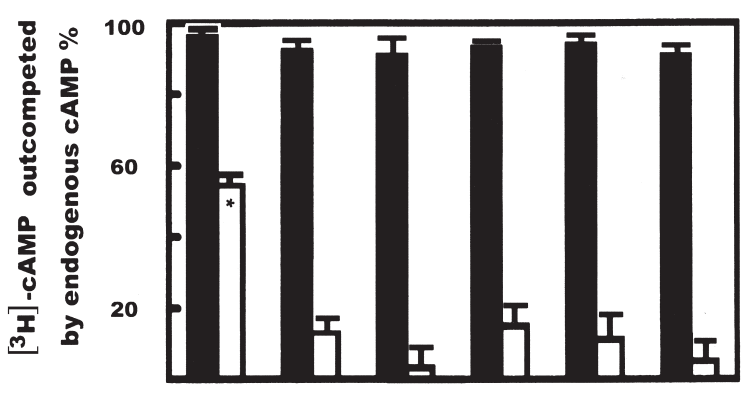

FRTL-5 WRO ARO ARO1 ARO2 ARO-neo

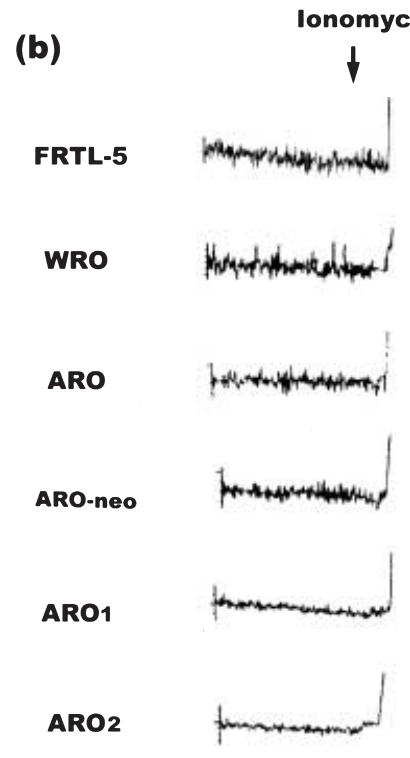

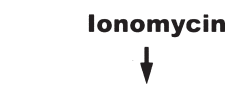

$\downarrow$
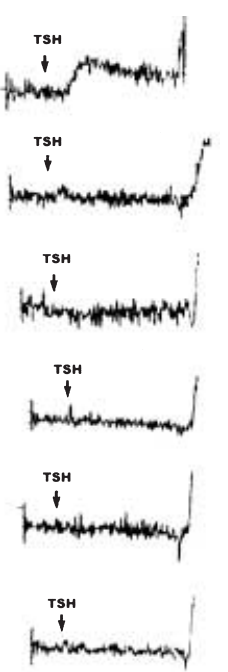

Figure 6 Response of TSH in terms of (a) intracellular CAMP, and (b) calcium influx of FRTL-5 cells, WRO cells, ARO cells and their TR $\beta 1$-overexpressing transfectants (ARO1, and ARO2). The CAMP and calcium responses were measured as described in Materials and Methods. (a) After incubation with $20 \mu \mathrm{M}$ forskolin, the endogenous cAMP outcompeted most $(>90 \%)$ of the $\left[{ }^{3} \mathrm{H}\right]$ cAMP in all cell lines. After incubation with $200 \mu \mathrm{IU} / \mathrm{ml} \mathrm{TSH}$, less than $15 \%$ of the $\left[{ }^{3} \mathrm{H}\right] \mathrm{cAMP}$ was outcompeted in the thyroid cancer cells, in contrast to more than $50 \%$ in the FRTL- 5 cells $\left({ }^{*}\right.$, stimulated with $100 \mu \mathrm{lU} / \mathrm{ml}$ ). Values are means \pm S.E.M. of three independent experiments. No significant difference was observed between ARO1, ARO2 and the parental ARO cells when the data were analyzed by paired Students $t$-test. (b) In contrast to the remarkable response generated in the FRTL- 5 cells induced by TSH $(\downarrow)$, none of the thyroid cancer cell lines responded to a bolus of $200 \mu \mathrm{IU} / \mathrm{ml}$ TSH $(\downarrow)$, despite the fact that a significant intracellular calcium influx was evoked by $10 \mathrm{mM}$ ionomycin ( $\mathbf{\downarrow}$ ).

\section{Discussion}

This study has shown that certain differentiation-associated molecular markers of the thyroid (TSHR, Tg, TTF-1 and

PAX-8), but not TPO genes, were preserved in the well-differentiated WRO cell line $\left(\mathrm{TSHR}^{+} \mathrm{Tg}^{+} \mathrm{TTF}-\right.$ $\left.1^{+} \mathrm{PAX}-8^{+} \mathrm{TPO}^{-}\right)$; in contrast, the levels of expression of these genes were remarkably reduced (except TTF-1) in the more primitive ARO cell line ( $\mathrm{TSHR}^{ \pm} \mathrm{Tg}^{-} \mathrm{PAX}-$ $\left.8^{-} \mathrm{TPO}^{-}\right)$. The finding of differentiation-status-related expression of PAX-8 in human thyroid cancer cell lines suggests that the transcription factor PAX-8 may be important for $\mathrm{Tg}$ gene expression in these cells. Although we do not know why the TPO gene was not expressed in both human thyroid cancer cell lines, the less effectively driven TPO promoter activity by PAX-8 (FrancisLang et al. 1992a) suggests that some other factors may participate in the regulation of TPO gene expression.

Despite the fact that TSHR gene is expressed exclusively in the thyroid, several non-thyroid-specific transcription factors also regulate TSHR gene expression (Kohn et al. 1995). By DNase $I$ protection and $T_{3}$ transactivation studies, Saiardi et al. (1994) demonstrated the existence of a TRE motif containing the half-site sequence (AGGTCA) to serve as a negative regulatory element in the $5^{\prime}$-flanking region of the rat TSHR gene. This suggests that the $T_{3-}-T R$ complex may modify the expression of TSHR in the thyroid. Although such regulation has not been proved by in vivo studies, an indirect line of evidence suggesting tight correlation between TSHR and TR genes is provided by the finding of concomitant loss of TR $\beta$ and TSHR gene expression in neoplastic thyroid tissues (Bronnegard et al. 1994). Therefore, it is highly possible that members of the TR gene family are involved in regulating the differentiation and neoplastic transformation of thyroid cells. To explore this idea, we used two human thyroid cancer cell lines with distinct differentiation status, which showed different phenotypic expression of thyroid-specific markers. It was also notable to find that the levels of expression of both TR $\beta 1$ protein and TSHR mRNA were remarkably lower in the anaplastic ARO cells than in the well-differentiated WRO cell line. To test the effect of TR $\beta 1$ overexpression on the regulation of thyroid-specific genes, the levels of expression of TSHR, Tg and TPO genes were examined in ARO cells stably transfected with a wtTR $\beta 1$ expression vector. Our observations that TR $\beta 1$ overexpression significantly upregulates the TRE-mediated luciferase reporter activity and the TSHR gene expression in two stable ARO transfectants are in agreement with the concept that overexpression of TR $\beta 1$ restores the $T_{3}$ response and promotes differentiation of neuroblastoma (Lebel et al. 1994) and thyrotropic tumor (Sarapura et al. 1997) cells. However, in accord with the observation of Bronnegard et al. (1994), the levels of expression of the other thyroid-specific genes (TPO, Tg, TTF-1 and PAX-8) were not changed.

On the basis of the observation of a $\mathrm{T}_{3}$-dependent inhibition of TSHR promoter activity in TR $\alpha 1-$ overexpressing CV1 cells, Saiardi et al. (1994) reported a 
short loop regulation of TSHR gene by TSH. They speculated that, through upregulation of the TR $\alpha 1$ gene, TSH downregulated TSHR gene expression in a TREsequence-dependent manner in FRTL-5 cells. Although knowledge as to how the $\mathrm{T}_{3-}-\mathrm{TR}$ complex regulates gene expression has advanced greatly recently, unresolved issues on the hormone-independent and cell-type-specific activities of TR (Munoz \& Berna1 997) remain to be explored.

Many nuclear cofactors are now known to participate in the complex regulation of gene expression (Koenig 1998). Among these cofactors, the corepressors complex with the unliganded TR to suppress the basal activities of genes positively regulated by $\mathrm{T}_{3}$, but facilitate transcription of genes negatively regulated by $T_{3}$ (Tagami et al. 1997). Thus overexpression of TR $\beta 1$ in our experiment may have created a status favoring the existence of excessive amounts of unliganded receptor and possibly, through the interaction with the corepressors, the upregulation of TSHR gene expression.

With regard to the effects of TR $\beta 1$ and TSHR overexpression on the growth rate of ARO cells, we observed a mitogenic effect by showing increases of DNA content and cell populations engaged in active DNA synthesis in the two stable ARO transfectants. Despite the fact that TSH induces the growth of normal thyroid, cancer cell lines of the thyroid frequently escape regulation by TSH. The signaling cascades coupled to the TSHR (Broecker et al. 1997, Metcalfe et al. 1998) were reported to be defective in WRO (Namba et al. 1993), HTh 74 (an anaplastic thyroid cancer cell line) and HTC-TSHr (Broecker et al. 1997) cell lines. In the present study, as TSH treatment did not induce either a protein kinase A (cAMP) or a protein kinase $\mathrm{C}$ (calcium influx) response, we assumed that the growth-promoting effect was TSHindependent. This assumption is in agreement with the observation by Morreti et al. (1997) that the cell proliferation was inhibited in ARO cells overexpressing wild-type p53 and TSHR. In contrast, DeFesi et al. (1985) reported that $T_{3}$ stimulates cell growth during the early G1 phase. Although the exact mechanism by which $\mathrm{T}_{3}$ regulates cell growth remains unknown, the fact that many growth- and cell-cycle-related proteins are regulated (Pastor et al. 1994, Bouterfa et al. 1995, Qi et al. 1999) or modulated (Qi et al. 1997, Barrera-Hernandez et al. 1998) by TR with or without the existence of $T_{3}$ suggests TR $\beta 1$ overexpression may contribute to the enhanced proliferation of the stable ARO transfectants. Nevertheless, the effect of TR $\beta 1$ overexpression on cell growth may be cell-type specific (Munoz \& Bernal 1997), because the overexpression of TR $\beta 1$ has been shown not to increase the DNA content of Neruo-2a cells (Lebel et al. 1994).

Finally, although both TR $\beta 1$ mRNA and protein were present in WRO cells, ARO cells showed abundant mRNA transcript, but undetectable TR $\beta 1$ protein. It is postulated that there are post-transcription or post- translation defects (or both) of the TR $\beta 1$ gene in the anaplastic ARO cell line. A similar TR $\beta 1$ expression pattern was observed in cell lines cultured from human hepatoma (Lin et al. 1994), neuroblastoma (Lebel et al. 1994) and thyrotropic tumor (Sarapura et al. 1997). This phenomenon might be related to the fact that these cells were cultured in vitro for a long period during which spontaneous mutation may occur and lead to loss of TR $\beta 1$ protein. Nevertheless, the demonstration of a posttranscription defect of the TR $\beta 1$ gene in two TSHsecreting pituitary adenomas (Gittoes et al. 1998) indicates that such a defect may also exist in vivo.

In summary, we found that the differentiation-related phenotypes were preserved in a well-differentiated thyroid cancer cell line, WRO. In contrast, the levels of expression of thyroid-specific molecular markers TSHR, Tg, TPO and PAX-8 were remarkably reduced in an anaplastic ARO cell line. The finding of a TR $\beta 1$ protein-deficit in the ARO cell line gave us the opportunity to analyze the effect of TR $\beta 1$ as a gene regulator in thyroid cancer cells. Our results suggest that induction of TR $\beta 1$ protein overproduction in clones of ARO cells stably transfected with the wtTR $\beta 1$ gene can lead to accelerated cell growth and enhanced TSHR gene expression.

\section{Acknowledgements}

The authors wish to dedicate this work to Dr Hong So Huang, without whose support and excellent comments this work could not have been accomplished. The authors also want to thank Drs HL Wang and CM Yang for their excellent help in the establishment of the assay system for the intracellular TSH response. This study was supported by grants CMRP-517 and CMRP-742 from ChangGung Memorial Hospital, Taipei, Taiwan, R.O.C.

\section{References}

Akiguchi I, Strauss K, Borges M, Silva JE \& Moses JE 1992 Thyroid hormone receptors and 3,5, $3^{\prime}$-triiodothyronine biological effects in FRTL-5 thyroid follicular cells. Endocrinology 131 1279-1287.

Barrera-Hernandez G, Zhan Q, Wong R \& Cheng SY 1998 Thyroid hormone receptor is a negative regulator in p53-mediated signaling pathways. DNA and Cell Biology 17 743-750.

Berlingieri MT, Akamizu T, Fusco A, Grieco M, Colletta G, Cirafici AM, Ikuyama S, Kohn LD \& Vecchio G 1990 Thyrotropin receptor gene expression in oncogene-transfected rat thyroid cells: correlation between transformation, loss of thyrotropin-dependent growth, and loss of thyrotropin receptor gene expression. Biochemical and Biophysical Research Communications 173 172-178.

Bouterfa HL, Piedrafita FJ, Doenecke D \& Pfahl M 1995 Regulation of $\mathrm{H} 1{ }^{\circ}$ gene expression by nuclear receptors through an unusual response element: implications for regulation of cell proliferation. DNA and Cell Biology 14 909-919.

Brabant G, Maenhaut C, Korle J, Scheumann G, Dralle H, Hoang-Vu C, Hesch RD, von zur Muhlen A, Vassart G \& Dumont JE 1991 Human thyrotropin receptor gene: expression in thyroid tumors and 
correlation to markers of thyroid differentiation and dedifferentiation. Molecular and Cellular Endocrinology $\mathbf{8 2}$ R7-R12.

Broecker M, Mayr GW \& Derwahl M 1997 Suppression of thyrotropin receptor- $\mathrm{G}$ protein phospholipase $\mathrm{C}$ coupling by activation of protein kinase $\mathrm{C}$ in thyroid carcinoma cells. Endocrinology 138 3787-3796.

Bronnegard M, Torring O, Boos J, Sylven C, Marcus C \& Wallin G 1994 Expression of thyrotropin receptor and thyroid hormone receptor messenger ribonucleic acid in normal, hyperplastic, and neoplastic human thyroid tissue. Journal of Clinical Endocrinology and Metabolism 79 384-389.

Cheng SY 1995 New insights into the structure and function of the thyroid hormone receptor. Jounal of Biomedical Science $\mathbf{2}$ 77-89.

DeFesi CR, Fels EC \& Surks MI 1985 L-Triiodothyronine $\left(T_{3}\right)$ stimulates growth of cultured GC cells by action early in the G1 period: evidence for mediation by the nuclear $\mathrm{T}_{3}$ receptor. Endocrinology 116 2062-2069.

Estour B, Van Herle AJ, Juillard GJF, Totanes TL, Sparkes RS, Giuliano AE \& Klandorf H 1989 Characterization of a human follicular thyroid carcinoma cell line (UCLA RO $82 \mathrm{~W}-1$ ). Virchows Archiv B Cell Pathology 57 167-174.

Fabbro D, DiLoreto C, Beltrami CA, Belfiore A, DiLauro R \& Damante G 1994 Expression of thyroid specific transcription factors TTF-1 and PAX-8 in human thyroid neoplasms. Cancer Research 54 4744-4749.

Field JB 1991 Mechanism of action of thyrotropin and other thyroid growth factors. In Werner and Ingbar's The Thyroid, edn 6, pp 276-287. Eds LE Braverman \& RD Utiger. Philadelphia: JB Lippincott Co.

Francis-Lang H, Price M, Polycarpou-Schwarz M \& DiLauro R 1992a Cell-type-specific expression of the rat thyroperoxidase promoter indicates common mechanisms for thyroid-specific gene expression. Molecular and Cellular Biology 12 576-588.

Francis-Lang H, Zannini M, DeFelice M, Berlingieri MT, Fusco A \& DiLauro R $1992 b$ Multiple mechanisms of interference between transformation and differentiation in thyroid cells. Molecular and Cellular Biology 12 5793-5800.

Gauthier K, Chassande O, Plateroti M, Roux JP, Legrand C, Pain B, Rousset B, Weiss R, Trouillas J \& Samaurt J 1999 Different functions for the thyroid hormone receptors $\operatorname{TR} \alpha$ and $\operatorname{TR} \beta$ in the control of thyroid hormone production and post-natal development. EMBO Journal 18 623-631.

Gittoes NJL, McCabe CJ, Verhaeg J, Sheppard MC \& Franklyn JA 1998 An abnormality of thyroid hormone receptor expression may explain abnormal thyrotropin production in thyrotropin-secreting pituitary tumors. Thyroid $\mathbf{8}$ 9-14.

Kimura S 1997 Role of the thyroid-specific enhancer-binding protein in transcription, development and differentiation. European Journal of Endocrinology 136 128-136.

Koenig RJ 1998 Thyroid hormone receptor coactivators and corepressors. Thyroid 8 703-713.

Kohn LD, Ban T, Okajima F, Shimura H, Shimura Y, Hidaka A, Giuliani C, Napolitano G, Kosugi S, Ikuyama S, Akamizu T, Tahara K \& Saji M 1995 Cloning and regulation of glycoprotein hormone receptor genes. In Molecular Endocrinology: Basic Concepts and Clinical Correlations, edn 1, pp 133-153. Ed BD Weintraub. New York: Raven Press Ltd.

Lebel JM, Dussault JH \& Puymirat J 1994 Overexpression of the $\beta 1$ thyroid receptor induces differentiation in Neuro-2a cells. Proceedings of the National Academy of Sciences of the USA 91 2644-2648.

Lin KH, Willingham MC, Liang CM \& Cheng SY 1991 Intracellular distribution of the endogenous and transfected $\beta$ form of thyroid hormone nuclear receptor visualized by the use of domain-specific monoclonal antibodies. Endocrinology 128 2601-2609.
Lin KH, Lin YW, Parkison C \& Cheng SY 1994 Stimulation of proliferation by $3,3^{\prime}, 5$-triiodo-L-thyronine in poorly differentiated human hepatocarcinoma cells over-expressing $\beta 1$ thyroid hormone receptor. Cancer Letters 85 189-194.

Lin KH, Lin YW, Lee HF, Liu WL, Chen ST, Chang KSS \& Cheng SY 1995 Increased invasive activity of human hepatocellular carcinoma cells is associated with an overexpression of thyroid hormone $\beta 1$ nuclear receptor and low expression of the anti-metastatic nm23 gene. Cancer Letters 98 89-95.

Lin KH, Zhu XG, Shieh HY, Hsu HC, Chen ST, McPhie P \& Cheng SY 1996 Identification of naturally occurring dominant negative mutants of thyroid hormone $\alpha 1$ and $\beta 1$ receptors in a human hepatocellular carcinoma cell line. Endocrinology 137 4073-4081.

Lin KH, Zhu XG, Hsu HC, Chen SL, Shieh HY, Chen ST, McPhie P \& Cheng SY 1997 Dominant negative activity of mutant thyroid hormone $\alpha 1$ receptors from patients with hepatocellular carcinoma. Endocrinology 138 5308-5315.

Metcalfe RA, Findlay C, Robertson WR, Weetman AP \& MacNeil S 1998 Differential effect of thyroid-stimulating hormone (TSH) on intracellular free calcium and cAMP in cells transfected with the human TSH receptor. Journal of Endocrinology 157 415-424.

Moretti F, Farsetti A, Soddu S, Misiti S, Crescenzi M, Filetti S, Andreoli M, Sacchi A \& Pontecorvi A 1997 p53 re-expression inhibits proliferation and restores differentiation of human thyroid anaplastic carcinoma cells. Oncogene 14 729-740.

Munoz A \& Bernal J 1997 Biological activities of thyroid hormone receptors. European Journal of Endocrinology 137 433-445.

Namba H, Yamashita S, USA T, Kimura H, Yokoyama N, Izumi M \& Nagataki S 1993 Overexpression of the intact thyrotropin receptor in a human thyroid cancer cell line. Endocrinology 132 839-845.

Ohta K, Endo T \& Onaya T 1991 The mRNA levels of thyrotropin receptor, thyroglobulin and thyroid peroxidase in neoplastic human thyroid tissues. Biochemical and Biophysical Research Communications 174 1148-1153.

Pastor R, Bernal J \& Rodriguez-Pena A 1994 Unliganded c-erbA/thyroid hormone receptor induces trkB expression in neuroblastoma cells. Oncogene 9 1081-1089.

Qi JS, Desai-Yajnik V, Yuan Y \& Samuels HH 1997 Constitutive activation of gene expression by thyroid hormone receptor results from reversal of p53-mediated repression. Molecular and Cellular Biology 17 7195-7207.

Qi JS, Yuan Y, Desai-Yajnik V \& Samuels HH 1999 Regulation of the $m d m 2$ oncogene by thyroid hormone receptor. Molecular and Cellular Biology 19 864-872.

Saiardi A, Falasca P \& Civitareale D 1994 The thyroid hormone inhibits the thyrotropin receptor promoter activity: evidence for a short loop regulation. Biochemical and Biophysical Research Communications 205 230-237.

Sarapura VD, Wood WM, Bright TM, Ocran KW, Gordon DF \& Ridgway CR 1997 Reconstitution of triiodothyronine inhibition in non-triiodothyronine-responsive thyrotropic tumor cells using transfected thyroid hormone receptor isoforms. Thyroid 7 453-461.

Schneider AB 1991 Carcinoma of follicular epithelium. In Werner and Ingbar's The Thyroid, edn 6, pp 1121-1165. Eds LE Braverman \& RD Utiger. Philadelphia: JB Lippincott Co.

Schuppert F, Deiters S, Rambusch E, Sierralta W, Dralle H \& von zur Muhlen A 1996 TSH-receptor expression and human thyroid disease: relation to clinical, endocrine, and molecular thyroid parameters. Thyroid 6 575-587.

Tagami T, Madison LD, Nagaya T \& Jameson L 1997 Nuclear receptor corepressors activate rather than suppress basal transcription of genes that are negatively regulated by thyroid hormone. Molecular and Cellular Biology 17 2642-2648. 
Zannini M, Francis-Lang H, Plachov D \& DiLauro R 1992 Pax 8, a paired domain-containing protein, binds to a sequence overlapping the recognition site of a homeodomain and activates transcription from two thyroid-specific promoters. Molecular and Cellular Biology 12 4230-4241.
Received 6 August 1999

Revised manuscript received 9 December 1999

Accepted 22 December 1999 